\title{
Obese patients lose weight independently of nutritional follow-up after bariatric surgery
}

\author{
Beatriz Helena Tess ${ }^{1 *}$, Veruska Magalhães Scabim², Marco Aurélio Santo ${ }^{3}$, Júlio César R. Pereira ${ }^{4}$ \\ ${ }^{1}$ Professor at the Department of Preventive Medicine, Faculty of Medicine, University of São Paulo, São Paulo, SP, Brazil \\ ${ }^{2}$ Nutritionist at the Division of Nutrition and Dietetics, Central Institute, Hospital das Clínicas, Faculty of Medicine, University of São Paulo, São Paulo, SP, Brazil \\ ${ }^{3}$ Head of the Metabolic and Bariatric Surgery Service, Division of Digestive Surgery, Department of Gastroenterology, Faculty of Medicine, University of São Paulo, São Paulo, SP, Brazi \\ ${ }^{4}$ Associate Professor at the Department of Epidemiology, Faculty of Public Health, University of São Paulo, São Paulo, SP, Brazil
}

\begin{abstract}
SUMmaRY
Study conducted at the Department of Preventive Medicine, Faculty of Medicine, University of São Paulo, São Paulo, SP, Brazil

Article received: 5/28/2014 Accepted for publication: $10 / 21 / 2014$

*Correspondence: Address: Av. Dr. Arnaldo, 455, $2^{\circ}$ andar, Cerqueira César São Paulo, SP - Brazi Postal code: 01246-903 Phone: (+55 11) 30617082 Fax: (+55 11) 30626018 beatriz.tess@usp.br

http://dx.doi.org/10.1590/1806-9282.61.02.139

Objective: to examine the association between preoperative body weight, adherence to postsurgical nutritional follow-up, length of postoperative period, and weight loss during the first 18 months among adults who have undergone bariatric surgery.

Methods: a retrospective cohort study was conducted on 241 consecutive patients who underwent open Roux-en-Y gastric bypass (RYGBP) from January 2006 to December 2008, in a teaching hospital in São Paulo (Brazil). Data were collected through hospital records review and the variables analyzed included sex, age, immediate preoperative weight, adherence to postsurgical nutritional visits and length of postoperative period. Proportional body weight reductions during the 18-month follow-up period were examined using generalized estimating equations.

Results: $81 \%$ ( $n=195$ ) of participants were female, with overall mean age of 44.4 \pm 11.6 years, mean preoperative weight of $123.1 \pm 21.2 \mathrm{~kg}$ and mean preoperative body mass index of $47.2 \pm 6.2 \mathrm{~kg} / \mathrm{m}^{2}$. The overall adherence to postoperative follow-up schedule was 51\% (95\%CI: 44.5-57.5\%). Preoperative body weight and adherence were not associated with proportional weight reduction (Wald's test $\mathrm{p}$ $>0.18$ ). Weight loss leveled off at the end of the 18-month follow-up period for both compliant and non-compliant patients (Wald's test $\mathrm{p}=0.00$ ).

Conclusions: our study showed that weight loss occurred steadily over the first 18 months after RYGBP, leveling off at around $40 \%$ weight reduction. It was associated with neither presurgical weight, nor nutritional follow-up and it may be primarily dependent on the surgical body alterations themselves. This finding may have implications for intervention strategies aimed at motivating patients to comply with early postsurgical and life-long follow-up.
\end{abstract} Conflict of interest: none
Keywords: morbid obesity, bariatric surgery, weight loss, lost to follow-up, Brazil.

\section{INTRODUCTION}

In the past two decades, research has provided evidence that bariatric surgery is an effective treatment of severe obesity compared with conventional nonsurgical therapy. ${ }^{1,2}$ The main objectives of such surgery are to promote significant and sustained body weight loss, to improve or resolve obesity-related comorbidities, ultimately promoting better quality of life with low rates of short and long-term complications. Life-long postoperative multi-professional follow-up has been recommended as a means of monitoring weight changes and comorbidities and of preventing adverse effects, such as multiple nutritional deficiencies. ${ }^{3-5}$
The importance of patient's postoperative clinical follow-up on weight changes after gastric bypass is still controversial. Some studies have found a positive association between weight loss and adherence to postsurgical appointments, ${ }^{6-8}$ whereas others have not found such an association. ${ }^{9}, 10$ The lack of consistent findings can be partially explained by the heterogeneity of methodologies including different study designs, sample sizes, lengths and definitions of follow-up, and variables measured such as types of bariatric surgery.

Body weight changes vary greatly among individuals, but understanding the predictors of postsurgical weight loss 
is important to inform bariatric services in order that specific strategies may be adopted to help patients overcome hurdles that may cause unsuccessful weight loss in the long term.

The present study aimed to investigate the association of preoperative weight, patient attendance at nutritional follow-up visits, duration of postoperative period and body weight loss during the first 18 month-period following bariatric surgery.

\section{Methods}

Between 2009 and 2010, a retrospective cohort study was conducted by examining medical records of 241 consecutive patients who had undergone first time open Roux-en-Y gastric bypass (RYGBP), under the public health system at the Hospital das Clínicas of the Medical School of University of São Paulo (Brazil) from January 1, 2006, to December 31, 2008. The main objective of the study was to estimate the prevalence of adherence to outpatient postoperative nutritional visits during the first 12 month follow-up period (the outcome of interest) and to explore the association between adherence and selected factors, such as age, sex, marital status, education, employment status, distance between home and hospital, presurgical body mass index (BMI), presence of one or more presurgical comorbidities and duration of hospitalization after surgery. Details have been published elsewhere. ${ }^{11}$

Based on this patient cohort, we proposed a complementary study to evaluate the association between preoperative body weight, adherence to postsurgical nutritional follow-up, length of postoperative period by trimester, and patients' body weight change during the first 18 months following surgery.

Data on age, sex, immediate preoperative weight and dates of attendance at postoperative nutritional visits during the first 12-month follow-up period were already part of the database created for the primary study. After institutional review board approval was obtained for the supplementary study, further data were collected from a second round of hospital record review. Information regarding dates of attendance at nutritional appointments between 12 and 18 months after surgery and body weight measures recorded on the outpatients' nutritional charts were added to the original database.

The standard postoperative nutritional schedule for the 18-month follow-up period included seven visits, namely at the $1^{\text {st }}, 2^{\text {nd }}, 3^{\text {rd }}, 6^{\text {th }}, 9^{\text {th }}, 12^{\text {th }}$ and $18^{\text {th }}$ months. For the purpose of this study, individuals who attended at least five of the seven planned visits were considered adherent.

The outcome of interest of this study was body weight loss after surgery over an 18-month period. Proportional reduction of body weight was calculated based on presurgical weight and weight measures recorded at each vis- it. It was defined as: [(weight in $\mathrm{kg}$ at the visit/presurgical weight in $\mathrm{kg}) \times 100]$.

Proportional body weight reductions attained by trimester were examined by means of generalized estimating equations (GEE), so that within-subject dependency could be accounted for, and missing values and the consequent unevenly spaced observations could be dealt with. ${ }^{12}$ Besides the effect of time over body weight reduction, the effects of adherence to follow-up, as a factor, and presurgical body weight at hospital admission, as a covariate, were analyzed together with their possible interactions.

\section{Results}

The main characteristics of the study population are shown in Table 1 . The majority were female. The overall adherence to postoperative follow-up schedule was $51 \%(123 / 241$, 95\%CI: 44.5-57.5\%). The two groups of compliant and non-compliant patients did not significantly differ, either in sex (chi-square, $\mathrm{p}=0.07$ ) or in preoperative body weight (T-test, $\mathrm{p}=0.219)$.

$\begin{aligned} & \text { TABLE } 1 \text { Baseline characteristics of patients submitted to } \\
& \text { gastric bypass between } 2006 \text { and 2008, in the city of São } \\
& \text { Paulo, Brazil. }\end{aligned}$
\begin{tabular}{ll} 
Characteristics & $\begin{array}{l}\text { All patients } \\
(\mathbf{n}=\mathbf{2 4 1})\end{array}$ \\
\hline Female sex (\%) & 81 \\
\hline Mean age at time of surgery (years) & $44.4 \pm 11.6$ \\
\hline Mean immediate preoperative weight $(\mathrm{kg})$ & $123.1 \pm 21.2$ \\
\hline Mean immediate preoperative $\mathrm{BMI}\left(\mathrm{kg} / \mathrm{m}^{2}\right)$ & $47.2 \pm 6.2$ \\
\hline
\end{tabular}

The 241 patients provided different numbers of records of proportional reduction of body weight at admission. Indeed, as shown in Table 2, 10 patients had no record at all and only eight had the six records corresponding to the six trimesters.

TABLE 2 Distribution of the number of valid records available for analysis.

\begin{tabular}{lll}
$\mathbf{N}^{\mathbf{0}}$ of valid records & $\mathbf{N}^{\mathbf{0}}$ of cases & \% of cases \\
\hline 0 & 10 & 4 \\
\hline 1 & 44 & 18 \\
\hline 2 & 51 & 21 \\
\hline 3 & 34 & 14 \\
\hline 4 & 45 & 19 \\
\hline 5 & 49 & 20 \\
\hline 6 & 8 & 3 \\
\hline Total & 241 & 100
\end{tabular}


Using GEE (linear model, link identity), the effects of adherence to nutritional follow-up and preoperative body weight were found not statistically significant (Wald chisquare $\mathrm{p}>0.18$ ) for both variables and their interaction. As to postoperative time, a significant effect was found (Wald chi-square $\mathrm{p}=0.000$ ). Table 3 shows that an increasing additive effect is observed up to the $5^{\text {th }}$ and $6^{\text {th }}$ trimesters, and reaches the end of the follow-up period with a $24.9 \%$ increase over the $1^{\text {st }}$ trimester; this shows a mean proportional weight reduction of $12.5 \%(\mathrm{SD}=4.24)$. The linear model showed a better fit than other alternatives and it was only for the $5^{\text {th }}$ trimester that the premise of normal distribution of residuals did not hold (Kolmogorov-Smirnov $Z$ test $\mathrm{p}=0.046$ ).

TABLE 3 Effects of time over proportional (\%) reduction of body weight at hospital visits as estimated by GEE

\begin{tabular}{lllll} 
Parameter & B & $\begin{array}{l}\text { 95\% Wald } \\
\text { confidence interval }\end{array}$ & & \\
\hline & & Lower & Upper & P value \\
\hline (Intercept) & 12.534 & 11.980 & 13.087 & 0.000 \\
\hline Trimester 1 & Contrast & & & \\
\hline Trimester 2 & 8.048 & 7.309 & 8.786 & 0.000 \\
\hline Trimester 3 & 12.985 & 11.750 & 14.219 & 0.000 \\
\hline Trimester 4 & 29.902 & 26.241 & 33.564 & 0.000 \\
\hline Trimester 5 & 35.890 & 31.851 & 39.929 & 0.000 \\
\hline Trimester 6 & 24.900 & 20.976 & 28.824 & 0.000 \\
\hline
\end{tabular}

Figure 1 summarizes the results of the GEE analysis. Body weight reduction seems to level off around $40 \%$ of body weight reduction at the end of the 18-month follow-up period. For both compliant and non-compliant patients, time showed a significant effect over weight loss (Wald's test $\mathrm{p}=0.00$ ).

\section{Discussion}

Bariatric surgery has become the treatment of choice for severely obese patients, because it often causes weight loss, remission of several obesity-related comorbidities and improvement in quality of life. It has been argued that patient's follow-up by interdisciplinary specialized group is important after surgery to monitor weight changes, medical comorbidities and long-term surgical adverse events, such as multiple nutrient deficits. ${ }^{2,13,14}$ Nevertheless, most major RYGBP series have shown a $60-50 \%$ postoperative follow-up rate at 1 year, which drops off dramatically with time. ${ }^{15}$ These estimates are similar to the overall adherence prevalence of $51 \%$ (95\%CI: $44.5-57.5 \%)$ during the 18-month follow-up period of our study.

Our results agree with some studies, ${ }^{9,10}$ which found that adherence to postsurgical clinical follow-up was not

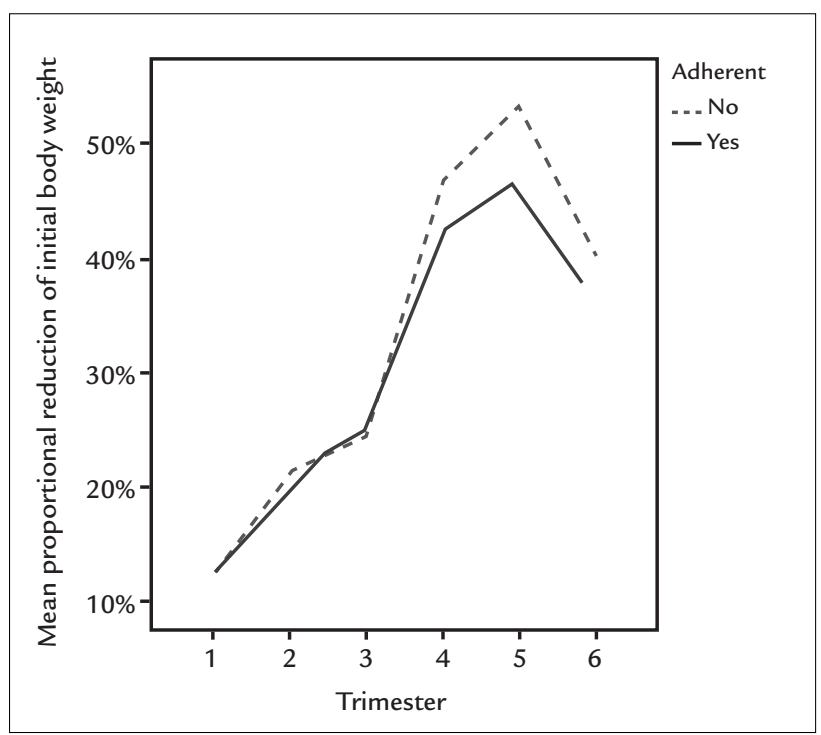

FIGURE 1 Body weight proportional reduction along the 18-month follow-up period of bariatric surgery patients.

associated with postoperative body weight loss, but differ from others. ${ }^{6-8}$ Conflicting findings may be due the variability in defining adherence to postsurgical visits, as well as the variability in distribution amongst study populations of many factors such as age, socio-economic status, health insurance type, and more. The relationship between adherence to aftercare programs and weight loss remains complex, and has not yet been successfully clarified. Ideally, a more standardized adherence definition should be widely adopted, which would generate more comparable betweenstudy data. Also, it is worth noting that there is some evidence to show that follow-up rates decrease with time, especially beyond 12 months after surgery (early attrition). Several authors argued that patients who stop attending postsurgical visits shortly after surgery might differ from patients who are lost to follow-up later in the multidisciplinary care program. ${ }^{4}, 15$ Evaluating early and late attrition separately when analyzing adherence factors may be particularly pertinent to further explore this issue.

Like Campos et al., ${ }^{16}$ our results did not reveal evidence that preoperative body weight was associated with postoperative weight loss. On the other hand, Ochner et al. ${ }^{17}$ found that greater initial BMI were associated with worse postsurgical weight loss outcomes, but recommended caution when making comparisons, since results may vary, depending on the weight loss measure chosen and the time of postoperative period. They argue that postsurgical weight loss occurs at a relatively steady rate in the first 12 months after surgery, regardless of preoperative BMI, and shows great variability among BMI categories after 12-month follow-up. 
It has been consistently reported that bariatric operations frequently lead to significant weight loss, which starts shortly after the surgical procedure, continues for some time and is thought to plateau for most individuals around 18 months after surgery, when maximal weight loss is reached. ${ }^{9,16-21}$ In our study, the GEE analysis suggested that the nadir of body weight loss occurs around the $4^{\text {th }}$ trimester after surgery, between the first and second years after surgery and this finding agrees with those previous reported.

The current study highlights an important gap in the bariatric surgery literature: the patterns of postoperative weight changes have neither been consistently reported nor comprehensively evaluated in adult patient populations, particularly after 12 months follow-up. This may affect the complex discussion about whether adherence to multidisciplinary aftercare program has an impact on the surgery outcomes. As reported by Harper et al., ${ }^{6}$ one of the main reasons for low follow-up attendance is that the patient is doing well during the first $12-18$ months ("honey-moon phase") and may feel that continual follow-up is not necessary. Similarly, Gourash et al. ${ }^{15}$ highlight the importance of putting into place diverse strategies to minimize attrition. In a recent review, Rudolph and Hilbert ${ }^{14}$ argued that continued postoperative behavioral management is especially important after 12-18 months, when weight loss decelerates or weight regain occurs.

Our study has limitations, mainly due to its retrospective design and short length of follow-up. The high attrition rate of postsurgical follow-up may have led to selection bias, by including those patients who are most concerned for their health. Individuals who adhere to follow-up appointments may also be more compliant with the postoperative lifestyle recommendations, resulting in better weight loss. Besides, our data only span 18 months after RYGBP and, as mentioned before, longer follow-up is required for a more thorough investigation of weight loss changes. Others factors that may have affected weight loss for which data were not available in the present study include physical activity and psychological support. These variables should receive greater emphasis in future studies.

If other studies, examining patterns of weight loss after surgery, do confirm that weight loss occurs regardless of attendance at multidisciplinary team visits, surgery candidates should be warned that weight loss will happen even if they do not return for their scheduled postoperative appointments in the short and medium term (during the first 18 months after surgery), and that most individuals experience optimal body weight loss at 12-18 months. At the same time, health professionals should reinforce the importance of permanent multidisciplinary care attendance as a crucial element for individualized clinical management. Patients should comprehend that by being monitored by the multi-professional team in the postsurgery period their specific needs will be matched, helping them to attain and to maintain the life-long benefits of surgery.

\section{Conclusion}

The results of our study showed that there was no evidence that percentage body weight loss during the first 18 months after bariatric surgery is associated with adherence to nutritional follow-up and presurgical weight. This may suggest that weight loss is governed by the effect of the surgical body alterations themselves and patients should be aware of that and be encouraged to adhere to postsurgical visits to avoid long term adverse events, such as weight regain and nutritional deficiencies. This finding may have implications for intervention strategies aimed at motivating patients to attend early postsurgical and life-long follow-up. Further studies are needed to understand weight change over a longer period of time after gastric bypass surgery, including the metabolic and underlying hormonal mechanisms associated with weight changes.

\section{Resumo}

Pacientes obesos perdem peso independentemente do seguimento nutricional pós-cirurgia bariátrica.

Objetivo: examinar a perda de peso nos primeiros $18 \mathrm{me}-$ ses em pacientes submetidos à cirurgia bariátrica.

Métodos: um estudo de coorte retrospectiva foi realizado com 241 adultos submetidos à gastroplastia, entre janeiro/2006 e dezembro/2008, em um centro em São Paulo (Brasil). Foi feita a revisão dos prontuários e as variáveis analisadas foram sexo, idade, peso pré-cirúrgico imediato, adesão ao seguimento nutricional pós-operatório e duração do período pós-operatório. A proporção do peso inicial perdido durante os 18 primeiros meses pós-cirurgia foi analisada pela técnica de equações generalizadas de estimação.

Resultados: $81 \%(n=195)$ eram mulheres; média de idade 44,4 $\pm 11,6$ anos; média de peso pré-operatório 123,1 \pm $21,2 \mathrm{~kg}$; média do índice de massa corporal $47.2 \pm 6.2 \mathrm{~kg} /$ $\mathrm{m}^{2}$. A prevalência de adesão ao seguimento nutricional pós-cirúrgico foi de 51\% (IC95\% = 44,5-57,5\%). Peso pré-cirúrgico e adesão não se mostraram significativamente 
associados à redução da proporção do peso inicial (Teste de Wald $p>0,18$ ). A perda de peso tendeu a diminuir no final do período de 18 meses pós-cirúrgico nos grupos de pacientes aderentes e não aderentes (Teste de Wald $\mathrm{p}=0,00)$.

Conclusão: nosso estudo mostrou que a perda de peso durante os primeiros 18 meses após a cirurgia chega a $40 \%$ do peso. O emagrecimento não foi associado ao peso pré-operatório, nem à adesão ao seguimento nutricional pós-cirúrgico e pode depender, principalmente, das alterações promovidas pelo procedimento cirúrgico em si. Esse achado poderá levar à proposição de intervenções para motivar os pacientes ao seguimento pós-operatório.

Palavras-chave: obesidade mórbida, cirurgia bariátrica, perda de peso, seguimentos, Brasil.

\section{References}

1. Adams TD, Davidson LE, Litwin SE, Kolotkin RL, LaMonte MJ, Pendleton RC, et al. Health benefits of gastric bypass surgery after 6 years. JAMA 2012; 308(11):1122-31.

2. Gloy VL, Briel M, Bhatt DL, Kashyap SR, Schauer PR, Mingrone G, et al. Bariatric surgery versus non-surgical treatment for obesity: a systematic review and meta-analysis of randomized controlled trials. BMJ 2013; 347:f5934.

3. Heber D, Greenway FL, Kaplan LM, Livingston E, Salvador J, Still C. Endocrine and nutritional management of the post-bariatric surgery patient: an Endocrine Society Clinical Practice Guideline. J Clin Endocrinol Metab 2010; 95(11):4823-43.

4. Moroshko I, Brennan L, O'Brien P. Predictors of attrition in bariatric aftercare: a systematic review of the literature. Obes Surg 2012; 22:1640-7.

5. Baptista V, Wassef W. Bariatric procedures: an update on techniques, outcomes and complications. Curr Opin Gastroenterol 2013; 29:684-93.

6. Harper J, Madan AK, Ternovits GA, Tichansky DS. What happens to patients who do not follow-up after bariatric surgery? Am Surgeon. 2007; 73(2):181-4.
7. Gould JC, Beverstein G, Reinhardt S, Garren MJ. Impact of routine and long-term follow-up on weight loss after laparoscopic gastric bypass. Surg Obes Relat Dis 2007; 3:627-30.

8. Compher CW, Hanlon A, Kang Y, Elkin L, Williams NN. Attendance at clinical visits predicts weight loss after gastric bypass surgery. Obes Surg 2012; 22:927-34

9. Shen R, Dugay G, Rajaram K, Cabrera I, Siegel N, Ren CJ. Impact of patient follow-up on weight loss after bariatric surgery. Obes Surg 2004; 14:514-9.

10. Welch G, Wesolowski C, Zagarins S, Kuhn J, Romanelli J, Garb J, et al. Evaluation of clinical outcomes for gastric bypass surgery: results from a comprehensive follow-up study. Obes Surg 2011; 21:18-28.

11. Scabim VM, Eluf-Neto J, Tess BH.Adesão ao seguimento nutricional ambulatorial pós-cirurgia bariátrica e fatores associados. Rev Nutr 2012; 25:497-506.

12. Hanley JA, Negassa A, Edwardes MDB, Forrester JE. Statistical analysis of correlated data using Generalized Estimating Equations: an orientation. Am J Epidemiol 2003; 157(4):364-75.

13. Dalcanale L, Oliveira CPMS, Faintuch J, Nogueira MA, Rondó P, Lima VMR, et al. Long-term nutritional outcome after gastric bypass. Obes Surg 2010; 20:181-7.

14. Rudolph A, Hilbert A. Post-operative behavioral management in bariatric surgery: a systematic review and meta-analysis of randomized controlled trials. Obes Rev 2013; 14:292-302.

15. Gourash WF, Ebel F, Lancaster K, Adeniji A, Iacono LK, Eagleton JK, et al. Longitudinal Assessment of Bariatric Surgery (LABS): Retention strategy and results at 24 months. Surg Obes Relat Dis 2013; 9:514-9.

16. Campos GM, Rabl C, Mulligan K, Posselt A, Rogers SJ, Westphalen AC, et al. Factors associated with weight loss after gastric bypass. Arch Surg 2008; 143(9):877-84

17. Ochner CN, Jochner MCE, Caruso EA, Teixeira J, Pi-Sunyer X. Effect of preoperative body mass index on weight loss after obesity surgery. Surg Obes Relat Dis 2013; 9:423-8.

18. Magro DO, Geloneze B, Delfini R, Pareja BC, Callejas F, Pareja JC. Longterm weight regain after gastric bypass: a 5 -year prospective study. Obes Surg 2008;18:648-51.

19. Valezi AC, Menezes MA, Mali Jr J. Weight loss outcome after Roux-en-Y Gastric Bypass: 10 years of follow-up. Obes Surg 2013; 23:1290-3.

20. Sjostrom L. Review of the key results from the Swedish Obese Subjects (SOS) trial - a prospective controlled intervention study of bariatric surgery. J Internal Med 2013; 273:219-34.

21. Courcoulas AP, Christian NJ, Belle SH, Berk PD, Flum DR, et al. Weight change and health outcomes at 3 years after bariatric surgery among individuals with severe obesity. JAMA 2013; 310(22):2416-25. 